J. Gen. Appl. Microbiol., 13, 73-83 (1967)

\title{
ENERGETIC AND NUCLEIC ANALYSES OF A CHEMOSTATIC CULTURE OF AZOTOBACTER VINELANDII
}

\author{
SHUICHI AIBA, SHIRO NAGAI, YOSHINORI NISHIZAWA \\ AND \\ MASAYUKI ONODERA
}

Institute of Applied Microbiology, University of Tokyo, Tokyo

(Received March 4, 1967)

\begin{abstract}
With a chemostatic culture of Azotobacter vinelandii, the values of yield factor for glucose were measured; the measurement was repeated after steady state in each value of dilution rate could be realized. In parallel with the measurement of yield factor, the bacterial cells sampled in each run of steady state were processed properly to determine the nucleic materials such as DNA, RNA and specific substances, the latter of which could be dissolved in a cold perchloric acid solution.

The glucose (limiting substrate) consumption by the cells was assumed to be a sum of that primarily due to cellular growth and that principally due to cellular maintenance. This assumption was justified experimentally. The efficiency of glucose utilization for cellular growth, $Y_{G}$, and the specific rate of glucose consumption for cellular maintenance, $m$, were 0.172 and $3.90\left(\mathrm{hr}^{-1}\right)$, respectively.

Although the contents of DNA and the acid-soluble substances remained fairly unchanged without regard to the values of dilution rate, a logarithmic relationship was confirmed between the RNA content, $\mathrm{N}_{R}$, and the value of dilution rate, $D$, or the specific growth-rate, $\mu_{X}$, of the bacterium.
\end{abstract}

It was confirmed experimentally in the previous paper (1) that the metabolic activity of Azotobacter vinelandii in a chemostatic culture was improved appreciably compared with that experienced in a batch system. A transient behavior of the bacterial cells was studied additionally by changing stepwise the dilution rate from one level to another in the continuous system: by using an Analog computer, it was found preliminarily that the change of environmental condition realized thus far by changing the dilution rate was followed immediately by the changes of both the values of specific growthrate and yield factor relevant to the microbial growth (1).

The experimental fact that the micro-organism was provided with a capacity of self-control depending on a change of the environmental condition seems worthy of due attention; a further insight into the metabolic activity of the microbe is needed before any rationale regarding both the steady and 
unsteady cultural conditions can be sorted out.

It is true that many workers have made respective approaches to the metabolic pattern of microbes in steady-state culture either chemostatically or turbidostatically (2-6) or by using a "replacement" ("shift-up" or "shift-down") culture $(9,10)$. Incidentally an analysis of dynamical property of microbes in unsteady culture has hardly been attempted except a few publications of FULD et al. (7) and MATELES et al. (8).

It is the principal purpose of this paper to make the energetic and nucleic analyses of Azotobacter vinelandii cultured in steady state. In that sense there seem to be no ingenious points in this account as compared with the preceding works published so far by the many workers $(11,12)$.

However, it seems to be of interest to compare and/or confirm the metabolic activities of this specific strain cultured chemostatically with reference to the data ever presented by other workers on a chemostatic culture of micro-organisms as a whole. In addition, it was absolutely necessary, prior to an analysis of transient behavior of the bacterium, to study the value of yield factor for glucose and the content of nucleic substances in steady-state continuous cultivation, both of which are expected to vary depending on the value of the dilution rate.

\section{MATERIAL AND METHOD}

The strain used in this work was Azotobacter vinelandii IAM 1078 (ATCC 9046). Before inoculation into a fermentor which will be described later, the microbes were cultured in shaken flasks (each capacity $=500 \mathrm{ml}$, working volume $=100 \mathrm{ml}$ ) at $30^{\circ}$ for about $20 \mathrm{hr}$.

The medium composition employed was a sort of the BuRK's medium, in which sucrose was replaced with glucose for ease of experimentation. The composition was as follows: Glucose $5.0 \mathrm{~g}, \mathrm{~K}_{2} \mathrm{HPO}_{4} 0.8 \mathrm{~g}, \mathrm{KH}_{2} \mathrm{PO}_{4} 0.2 \mathrm{~g}$, $\mathrm{MgSO}_{4} \cdot 7 \mathrm{H}_{2} \mathrm{O} 0.2 \mathrm{~g}, \mathrm{NaCl} 0.2 \mathrm{~g}$, sodium citrate $0.05 \mathrm{~g}, \mathrm{FeSO}_{4} \cdot 7 \mathrm{H}_{2} \mathrm{O} 0.005 \mathrm{~g}$, $\mathrm{Fe}_{2}\left(\mathrm{SO}_{4}\right)_{3} \cdot 3 \mathrm{H}_{2} \mathrm{O} 0.005 \mathrm{~g}, \mathrm{Na}_{2} \mathrm{MoO}_{4} \cdot 2 \mathrm{H}_{2} \mathrm{O} 0.001 \mathrm{~g}, \mathrm{CaCl}_{2} \cdot 2 \mathrm{H}_{2} \mathrm{O} \quad 0.01 \mathrm{~g}$, tap water $1,000 \mathrm{ml}, \mathrm{pH}=7.0-7.2$.

\section{Experimental procedure}

The cells harvested from the pre-cultivation were inoculated into a fermentor (nominal volume $=29$ liter, working volume $=13$ liter) in which the medium sterilized beforehand had been charged. The fully-baffled fermentor, equipped with a standard flat-blade turbine was operated at $30^{\circ}$; the rotational speed of the impeller and the aeration rate used were $750 \mathrm{rpm}$ and 2 vvm. For further details of the fermentor and the auxiliary equipment to have secured a continuous cultivation of the bacterium, refer to the previous report (1).

At a specific time of batch-cultivation, a supply of the sterile and fresh medium which had been stored in a reservoir of stainless steel was initiated 
to start a continuous run. If the cellular and substrate concentrations measured so far in each continuous run (see later) did not change its level for a considerable period of time for about $10 \mathrm{hr}$, the operation was assumed to be in steady state. During the steady state the sampling was made from time to time at pertinent intervals to determine the cellular concentration, the residual sugar concentration and the concentration of nucleic materials. In order to avert any possibility that dissolved oxygen becomes a limiting substrate a Beckman oxygen-probe was inserted into the broth to check conveniently the level of dissolved oxygen in each run operated at a specific value of dilution rate.

Determination of concentrations of cellular material, residual glucose and nucleic substances

The cellular concentration was determined with an electrophotometer (Model FPW-4, Hitachi Works, Ltd.) at a wave length of $610 \mathrm{~m} \mu$. The value of optical density $(\mathrm{OD} / \mathrm{ml})$ could be converted to dry cell-mass concentration $(\mathrm{mg} / \mathrm{ml})$. The residual glucose was measured with the SomogyI method.

Before proceeding to describe the nucleic analysis it seems necessary to refer to a procedure employed in this account to have prepared each sample of bacterial cells; the sampled broth was cooled down quickly to $0^{\circ}$ and centrifuged (about $2,000 \times g$ ) at $0^{\circ}$ for $10 \mathrm{~min}$. The cells were rinsed with cold saline water $(0.8 \%)$, and then centrifuged again (about $10,000 \times g$ ) at $0^{\circ}$ for $5 \mathrm{~min}$. The washed cells were frozen with a mixture of acetone and dry ice $\left(-20^{\circ}\right)$ and subjected to another centrifugation (about $10,000 \times g$ ) for 5 min. The cells obtained thus far were treated with the same procedure of re-freezing $\left(-20^{\circ}\right)$ and re-centrifugation (about $10,000 \times g$ for $5 \mathrm{~min}$ ).

The bacterial cells inactivated so far with the acetone-dry ice mixture $\left(-20^{\circ}\right)$ were dried eventually in a vacuum desiccator until a powder-like material was obtained. The powdered material could be stored without any appreciable degradation. Consequently, it was possible to make the nucleic analysis with several different samples simultaneously. Regarding the procedure of extracting RNA, DNA and other nucleic substances from the powder-like samples, the SCHMIDT-THANNHAUSER-SCHNEIDER method was consulted (13). The nucleic materials extracted properly by the afore-mentioned method were measured with a UV spectro-photometer (Type SV-50 A, Shimazu Co., Ltd.) at a wavelength of $260 \mathrm{~m} \mu$.

\section{RESULTS AND DISCUSSION}

Regarding the concentrations of (dry) cell mass, $X$, and limiting substrate (glucose), $S$, in single vessels of continuous run, the following equations can be obtained (material balance).

$$
\text { For } X, \quad \frac{d X}{d t}=-D X+\left(\frac{d X}{d t}\right)_{\text {Growth }}=-D X+\mu_{X} X
$$




$$
=\left(\mu_{X}-D\right) X
$$

For $S, \quad \frac{d S}{d t}=D\left(S_{0}-S\right)+\left(\frac{d S}{d t}\right)_{\text {Consumption }}$

$$
=D\left(S_{0}-S\right)-\frac{1}{Y} \mu_{X} X
$$

provided: $S_{0}=$ substrate concentration in fresh medium $(\mathrm{mg} / \mathrm{ml}), \mu_{X}=$ specific growth-rate $\left(\mathrm{hr}^{-1}\right), Y=$ yield factor $(=-\Delta X / \Delta S), D=$ dilution rate $\left(\mathrm{hr}^{-1}\right)$.

In steady state for $X$ and $S$, the above material-balance equations are reduced as follows:

$$
\begin{gathered}
\mu_{X}=D \\
Y=\frac{X}{S_{0}-S}
\end{gathered}
$$

The experimental data on $X$ vs. $D$ and $S$ vs. $D$ are shown in Fig. 1; the ordinate represents either the cellular concentration, $X(\mathrm{mg} / \mathrm{ml})$ or the substrate concentration, $S(\mathrm{mg} / \mathrm{ml})$, while the abscissa is the dilution rate, $D$ $\left(=\mu_{X}\right.$ in steady-state condition in single vessels) $\left(\mathrm{hr}^{-1}\right)$.

It is seen from the figure that the "wash out" occurs in this example around the value of $D=0.275\left(\mathrm{hr}^{-1}\right)$. Judging from the data in the figure, it is clear that the value of $Y$ deteriorates with the decrease of specific growth rate, $\mu_{X}$ (=D in this instance). Since the broth was low in viscosity, and in addition, since the cellular concentration in question was rather dilute, far from such concentration as to make the broth exhibit the non-Newtonian

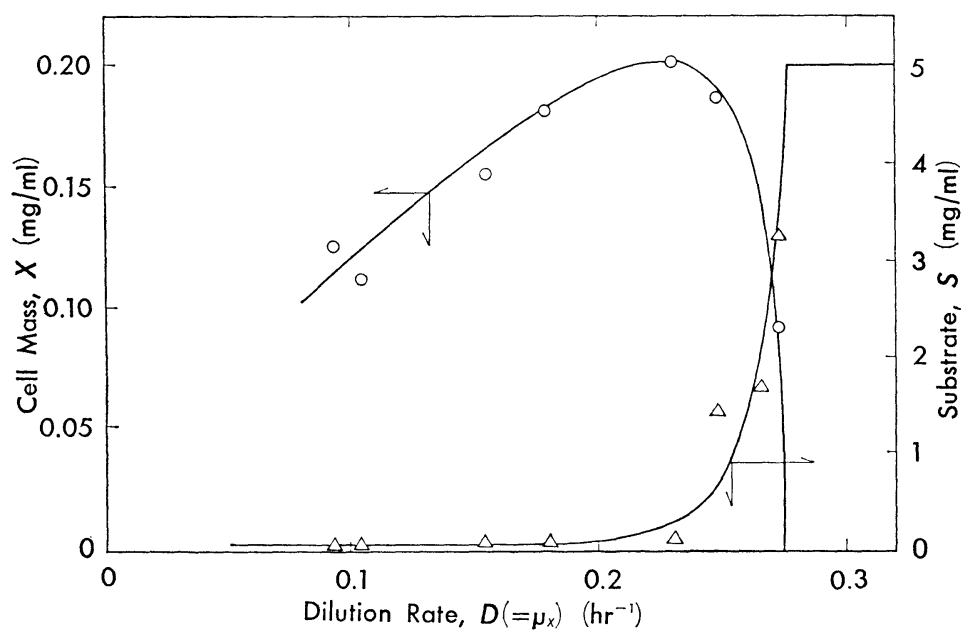

Fig. $1 . \quad X$ vs. $D$ and $S$ vs. $D$ observed. 


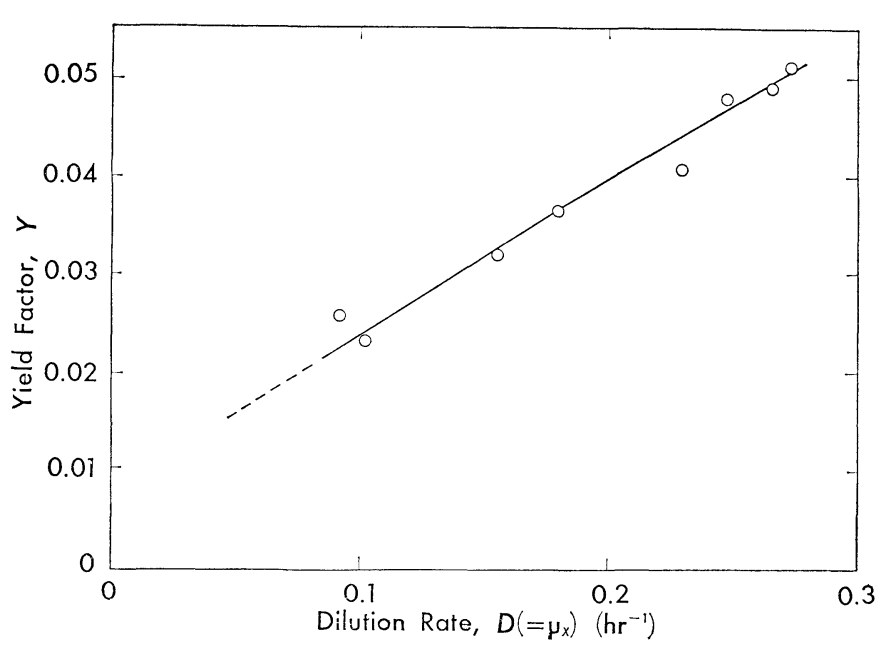

Fig. 2. Yield factor, $Y$, as varied by dilution rate.

characteristics, the above-mentioned deterioration of $Y$ value accompanying the decrease of $\mu_{X}$ value might have been inherent in the bacterial cells rather than in the environmental condition.

The value of $Y$ which was derived from the data points in Fig. 1 by using Eq. (4) was plotted against the value of dilution rate, $D$, as shown in Fig. 2. It is clear that the yield factor, $Y$, depends appreciably on the operating condition of $D$ in this example of continuous cultivation.

Now, an implication of the yield factor, $Y$, will be discussed further below. The consumption of glucose is assumed here to be attributable to that due to the cellular growth and that primarily due to the cellular maintenance as shown in the following equation. This sort of assumption is not too much sophisticated as can be seen from other publications; for instance see a paper presented by PIRT (14).

Then,

$$
(\Delta S)_{\text {Total }}=(\Delta S)_{\text {Growth }}+(\Delta S)_{\text {Maintenance }}
$$

$$
\begin{aligned}
Y & =-\frac{\Delta X}{(\Delta S)_{T}} \\
& =-\frac{\Delta X}{(\Delta S)_{G}+(\Delta S)_{M}}
\end{aligned}
$$

Another factor, $Y_{G}$, which is particularly concerned with an efficiency of glucose utilization for the cellular growth is defined as follows:

$$
Y_{G}=-\frac{\Delta X}{(\Delta S)_{G}}
$$


By differentiating both sides of Eq. (5) with time, $t$,

$$
\left(-\frac{d S}{d t}\right)_{T}=\left(\frac{d S}{d t}\right)_{G}+\left(\frac{d S}{d t}\right)_{M}
$$

From the definition of $Y$ and $Y_{G}$,

$$
\left.\begin{array}{l}
\left(\frac{d S}{d t}\right)_{T}=-\frac{1}{Y} \mu_{X} X \\
\left(\frac{d S}{d t}\right)_{G}=-\frac{1}{Y_{G}} \mu_{X} X
\end{array}\right\}
$$

It is assumed here that the rate of glucose consumption primarily due to the cellular maintenance, $(d S / d t)_{M}$, is proportional to the value of cellular concentration, $X$, in current at a particular period of time.

$$
\left(\frac{d S}{d t}\right)_{M}=-m X
$$

where

$m=$ proportionality constant,

$=$ specific rate of glucose consumption for cellular maintenance.

Substituting Equns. (9) and (10) into Eq. (8), the following relationship between $Y$ and $\mu_{X}$ is obtained.

$$
\frac{1}{Y}=\frac{m}{\mu_{X}}+\frac{1}{Y_{G}}
$$

The data points in Fig. 2 were converted to those in Fig. 3, in which the value of $1 / Y$ was plotted against the reciprocal of dilution rate, $1 / \mathrm{D}$.

It may be plausible to infer from the figure that Eq. (11) was justified by the experimental data and a straight line drawn through the data points in Fig. 3 was assumed to represent the equation. This implies that the values of $m$ and $1 / Y_{G}$ are 3.90 and 5.8, respectively, as shown in the figure: these values of $m$ and $Y_{G}$ may depend on the specific strain and cultural conditions used.

Fig. 4 is another representation of the straight line drawn in Fig. 3; the upper diagram of the figure was prepared to clarify the experimental relationship obtained between each reciprocal of the yield factors and the dilution rate. It is evident from the upper diagram that the efficiency of glucose utilization for the cellular maintenance is enhanced with the increase of specific growth rate of the bacterium used, while the efficiency for the cellular growth remains unchanged without regard to the specific growthrate of the microbe: the over-all efficiency of glucose utilization is deteriorated thus far in parallel with the decrease of the specific growth-rate of the strain as is also clear from the upper diagram of Fig. 4. 


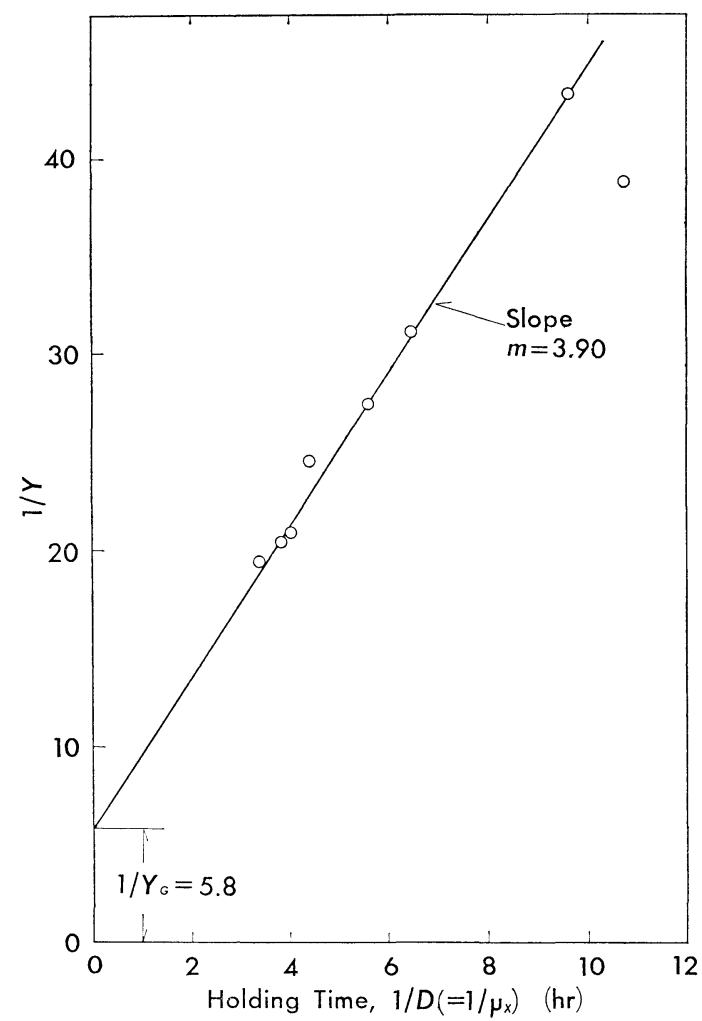
$1 / D$.

Fig. 3. Re-plotting the data (in Fig. 2) in terms of $1 / Y$ vs.

This kind of energetic picture regarding the bacterial growth is modified when the specific rates of the substrate utilization are taken into account. The specific rates of glucose utilization were plotted against the dilution rate in the lower diagram in Fig. 4; the diagram with respect to each line in the figure can be envisaged from the straight line assumed in Fig. 3 and respective formulae defined by Equns. (8), (9) and (10). It is noted from the figure that the specific rate of glucose utilization for the cellular maintenance remains unchanged without respect to the dilution rate, while those for the cellular growth and for the over-all term increase linearly with the increase of specific growth-rate (=dilution rate in steady state of continuous culture in single vessels) of the bacterium employed.

To recapitulate, it is of significance to note from Fig. 4 that the limiting substrate (glucose) consumed in a lower range of specific growth-rate of the bacterium is devoted principally to maintain the cell mass synthesized so far (upper diagram), while the specific rate of glucose consumption for the cellular maintenance remains unaltered irrespective of the specific growth-rate of the 


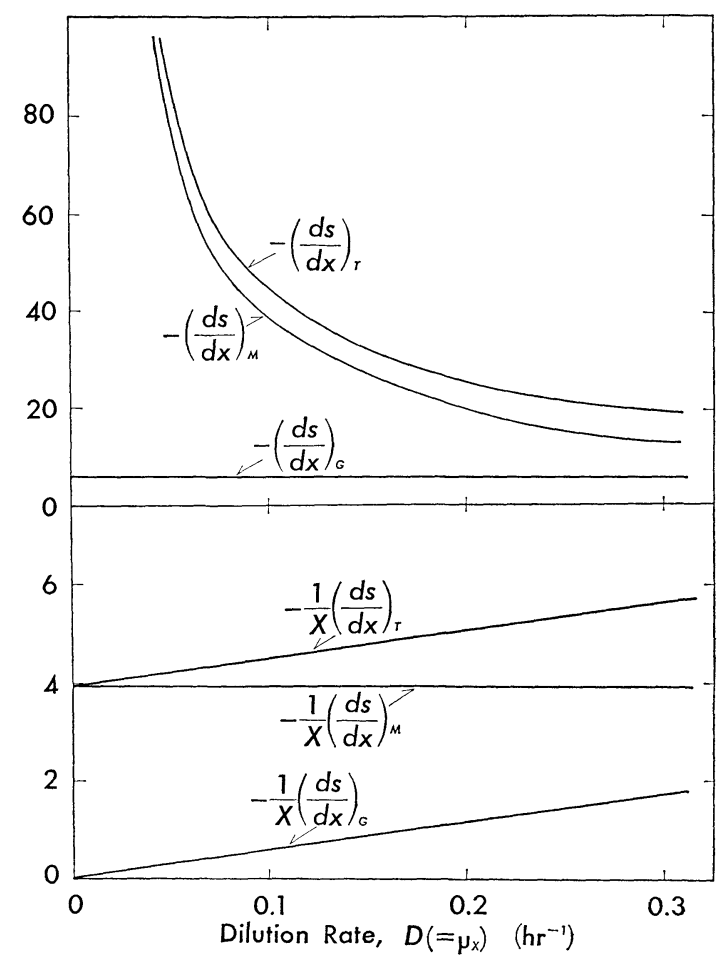

Fig. 4. Metabolic activities of Azotobacter vinelandii as varied with the change of $D$.

The upper diagram shows reciprocals of yield factors, while the lower one indicates specific rates, both of which are dependent or independent on/or of the values of $D$.

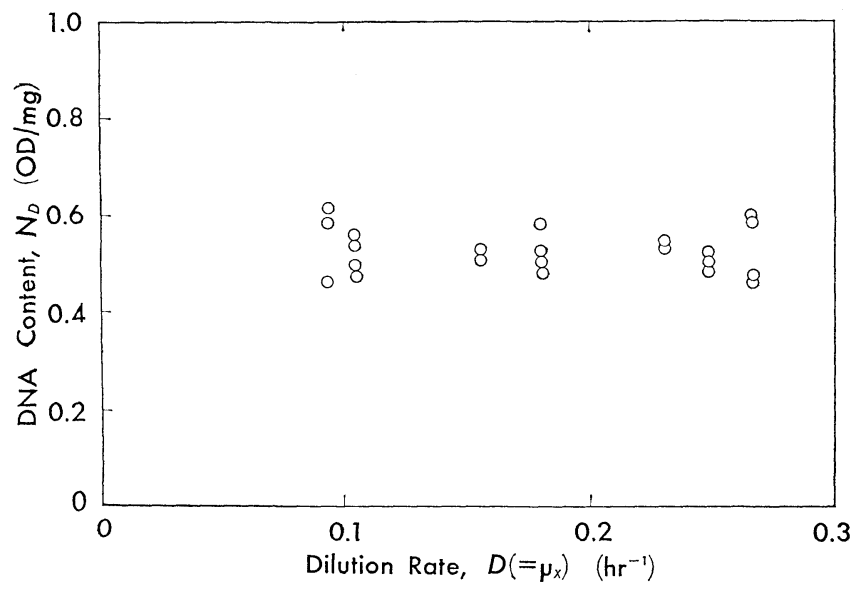

Fig. 5. $N_{D}$ vs. $D$. 


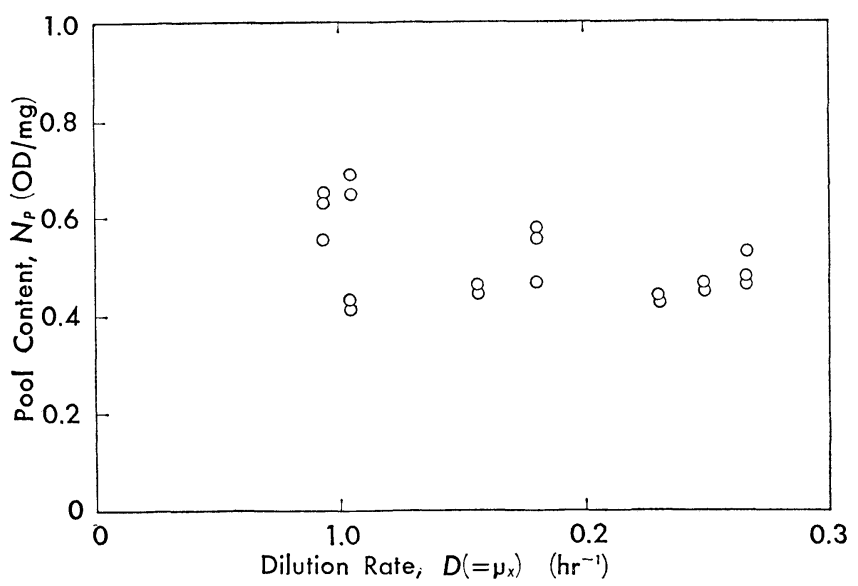

Fig. 6. $N_{P}$ vs. $D$.

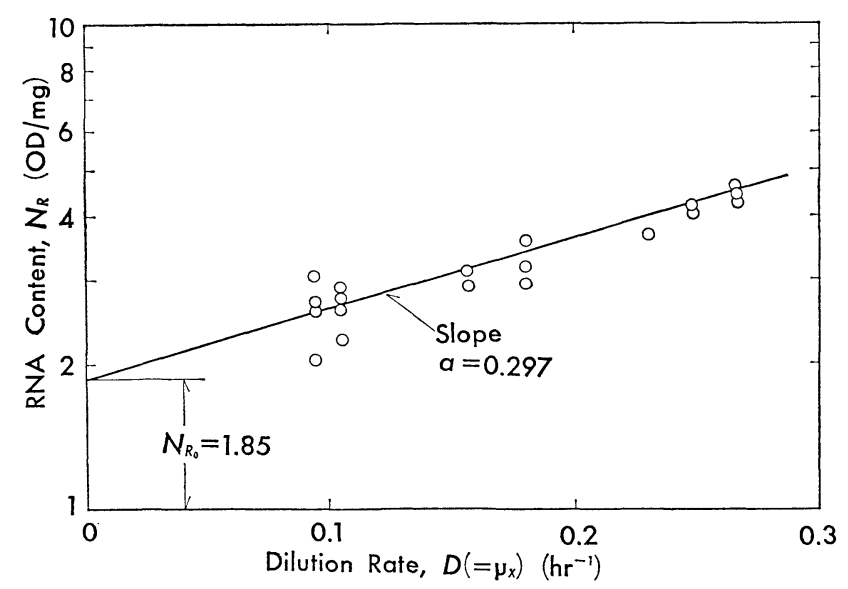

Fig. 7. $N_{R}$ vs. $D$.

strain (lower diagram). It is surmised that this sort of energetic map of a bacterial growth seems to be worthy of proper attention, if one considers other cases than a specific one illustrated here, though the concrete evidence remains to be studied from case to case when required.

Next, the energetic picture will be discussed from another angle of nucleic acid content. The contents of DNA and a specific material which could be dissolved in a cold perchloric acid (the so-called nucleotide pool) were plotted against the dilution rate as shown in Figs. 5 and 6 . It is seen from these figures that the contents were least affected by the specific growthrate of the strain. By using an average conversion factor from OD to $\mathrm{mg}$ regarding DNA and RNA content for bacteria (13), the DNA content as 
illustrated in Fig. 5 corresponded to a level of 2.5\% in terms of $\mathrm{mg}$ per $\mathrm{mg}$ cell and the RNA was in a level of $15 \%$ (see the value of RNA content of $3 \mathrm{OD} / \mathrm{mg}$ in Fig. 7 later).

The content of RNA as varied by the dilution rate is shown in a semilogarithmic paper of Fig. 7; the ordinate is the RNA content in terms of $\mathrm{OD} / \mathrm{mg}$, while the abscissa is the dilution rate experienced in each steady state and continuous run of this account.

It is remarked from the figure that the RNA content is affected logarithmically by the value of specific growth-rate as follows:

$$
\mu_{X}=a \ln \frac{N_{R}}{N_{R_{0}}}
$$

provided: $\mu_{X}=$ specific growth-rate $\left(\mathrm{hr}^{-1}\right), N_{R}=\mathrm{RNA}$ content $(\mathrm{OD} / \mathrm{mg}), N_{R_{0}}=$ RNA content of dormant cells $(\mathrm{OD} / \mathrm{mg}), a=$ empirical constant $\left(\mathrm{hr}^{-1}\right)$.

The values of $N_{R_{0}}$ and $a$ which are described in Fig. 7 are inherent to the cells employed; these values may be subjected to change depending on cultural and environmental conditions.

Although the correlation secured so far between the RNA content and the specific growth-rate in a continuous and steady-state cultivation of the microbe (Fig. 7) is not a new finding, it is, nevertheless, of significance to confirm the logarithmic relation between the values of $N_{R}$ and $\mu_{X}$ in this specific strain and cultural condition studied here.

\section{NOMENCLATURE}

$a:$ proportionality constant

$D$ : dilution rate $(=F / V)\left(\mathrm{hr}^{-1}\right)$

$F \quad$ : feed rate $\left(\mathrm{m}^{3} / \mathrm{hr}\right)$

$m$ : proportionality constant (=specific rate of glucose consumption for cellular maintenance) ( $\mathrm{mg}$ glucose $/ \mathrm{mg}$ cell $\mathrm{hr}$ )

$N_{D}:$ DNA content (OD/mg cell)

$N_{P}$ : content of specific substances which can be dissolved into cold perchloric acid $(O D / m g$ cell)

$N_{R_{0}}$ : RNA content of cells which are infinitesimal in growth rate (dormant cells) (extrapolated value) $(\mathrm{OD} / \mathrm{mg}$ cell)

$N_{R}:$ RNA content (OD/mg cell)

$S_{0}$ : limiting substrate concentration in fresh medium $(\mathrm{mg} / \mathrm{ml})$

$S$ : limiting substrate concentration $(\mathrm{mg} / \mathrm{ml})$

$t \quad$ : time (hr)

$V$ : liquid volume $\left(\mathrm{m}^{3}\right)$

$X$ : cell-mass concentration $(\mathrm{mg} / \mathrm{ml})$

$Y_{G}:$ yield factor for growth $(=-\Delta X / \Delta S)$

$Y$ : yield factor $\left(=-\Delta X /(\Delta S)_{T}\right)$

Greek letter

$\mu_{X}:$ specific growth-rate $\left(\mathrm{hr}^{-1}\right)$ 
subscript

$G:$ growth

$T:$ total

$M$ : maintenance

\section{REFERENCES}

1) S. Aiba, S. Nagai and Y. Nishizawa: J. Ferm. Technol., 45, 452 (1967).

2) J. Monod: Ann. Inst. Pasteur, 79, 390 (1950).

3) A. Novick and L. Szilard: Proc. Nat. Acad. Sci., Wash., 36, 708 (1950).

4) R. K. Finn and R. E. Wilson: Agr. Food Chem., 2, 66 (1954).

5) D. Herbert: In Continuous Culture of Micro-organisms, S. C. I. Monograph No. 12, Society of Chemical Industry, London (1961), p. 21.

6) D. Herbert: In 11th Symposium of the Society for General Microbiology, Cambridge University Press, Cambridge (1961), p. 391.

7) G. J. Fuld, R. I. Mateles and B. W. Kusmierek: In Continuous Culture of Micro-organisms, S. C. I. Monograph No. 12, Society of Chemical Industry, London (1961), p. 54.

8) R. I. Mateles, D. Y. Ryu and T. Yasuda: Nature, 208, 263 (1965).

$9)$ N. O. KJeldgaard, O. Maal $\Phi$ e and M. Schaechter: J. Gen. Microbiol., 19, 607 (1958).

10) F. C. Neidhardt and B. Magasanik: Biochim. Biophys. Acta, 42, 99 (1960).

11) K. L. Schulze and R. S. Lipe: Archiv für Mikrobiol., 48, 1 (1964).

12) P. W. Tempest and D. Herbert: J. Gen. Microbiol., 41, 143 (1965).

13) S. Mizuno: Kagaku to Seibutsu (Chemistry and Biology) 3, 148 (1965), in Japanese.

14) S. J. Pirt: Proc. Roy. Soc., B 163, 224 (1965). 